cisternal A-particle genome, it was indeed possible to demonstrate that the insertion of this sequence into c-mos resulted in its activation $^{9.10}$.

Institute of Hematology,

G. REchavi

Chaim Sheba Medical Center,

Tel-Hashomer 52621, Israel

Israeli Institute for

N. KATZIR

Biological Research,

Nes-Ziona, PO Box 19, Israel

Department of Chemical Immunology,

Weizmann Institute of Science,

Rehovot 76100, Israel

1. Morse, B., Rotherg, P.G., South, V.J., Spandorfer, J.M. \& Astrin, S.M. Nature 333, 87-90 (1988).

2. Fanning, T.G. \& Singer, M.F. Biochim. biophys. Acta 910 , 203-212 (1987).

3. Kozbor, D. \& Croce, C.M. Cancer Res. 44, 438 (1984)

4. Escot, C. et al. Proc. natn. Acad. Sci. U.S. A. 83, 4834 (1986).

Katzir N etal. Proc. natn. Acad. Sci. U.S.A. 82, 1054 (1985)

Katzir, N. et al Oncogene 1, 445-448 (1987)

7. Pear, W.S., Wahlstrom, G. \& Nelson, S.F. Molec. cell. Pear. W.S., Wahlstrom
Biol. 8, 441-451 (1988).

8. Farabaugh, P.J. \& Fink, G.R. Nature 286, 352 (1980)

9. Rechavi, G., Givol, D. \& Canaani, E. Nature 300, 607 $611(1982)$

10. Cohen, J.B., Unger, T., Rechavi, G., Canaani, E. \& Givol, D. Nature 306, 797-799 (1983).

\section{DNA and the hydration economy}

SiR-The proposal ${ }^{1}$ that DNA conformation is determined by "economics in the hydration of phosphate groups" has aroused considerable interest ${ }^{2}$. Central to this hypothesis is the fact that in the Aand Z-forms of DNA the distance between adjacent phosphate groups along the polynucleotide chain is shorter than that in the B-form, so that although a water molecule could form a hydrogen-bonded bridge between successive phosphates in $\mathrm{A}$ and $\mathrm{Z}$ this is not possible for $\mathrm{B}$. These proposals are based on a survey of the distances between charged phosphate oxygens in adjacent nucleotides and of the location of water oxygens in 13 oligonucleotide structures. The hydration of phosphate groups in the $\mathrm{A}$ - and $\mathrm{Z}$-forms is characterized as "economical" in contrast to the situation in B-DNA where the various phosphate groups are said to be "individually hydrated". This concept of "hydration economy" is proposed as the underlying cause for the $\mathrm{B} \rightarrow \mathrm{A}$ and $\mathrm{B} \rightarrow \mathrm{Z}$ transitions, both of which occur when the degree of hydration of the DNA is reduced, on the grounds that dehydration will favour those conformations which interact more economically with water molecules.

Saenger et al. ${ }^{1}$ also consider the effect of salt and organic polar solvents on the conformation adopted by DNA and conclude that "if salt or an organic polar solvent is added, water molecules are withdrawn from the DNA and hydration consequentially becomes more economical". From this argument, salt near the DNA would be expected to favour the "more economical structures", that is, A and $\mathrm{Z}$ rather than $\mathrm{B}$. It has been known for many years ${ }^{3}$ that this is not the case for the sodium salt of DNA. X-ray diffractions of fibres $^{4}$ and Raman spectroscopy ${ }^{5}$ show that low levels of salt favour $A$ whereas high levels favour B. It is clear, therefore, that the proposal that "hydration economy" determines DNA conformation cannot be correct.

Saenger et al. do not mention the Dform of DNA, whose occurrence for $\operatorname{poly}[d(A-T)]$.poly $[d(A-T)]$ has been known for 25 years ${ }^{6}$. We have shown that the transition between the D and B conformations can be followed in timeresolved X-ray fibre-diffraction studies using the SERC Daresbury Laboratory Synchrotron Radiation Source ${ }^{7.8}$. This transition is induced by varying the hydration of the fibre, with dehydration leading to the assumption of $\mathrm{D}$. The relevance of the D-form stems from its occurrence being favoured by relatively low levels of hydration and relatively high levels of salt ${ }^{9}$. The separation of charged phosphate oxygens along a polynucleotide chain in the D-form ${ }^{10}$ is about $7 \AA$, significantly longer than the 4.4 and $4.8 \AA$ in the $\mathrm{Z}$-form and 5.3 and $5.4 \AA$ in the $\mathrm{A}$-form, and comparable with the $6.6 \AA$ in the $\mathrm{B}$ form quoted by Saenger et al. These observations provide further evidence against the 'hydration economy' concept, which predicts that phosphate groups in D should, like those in $\mathrm{B}$, be individually hydrated and hence favoured by high levels of hydration. In contradiction to this prediction, our studies demonstrate that the $\mathrm{D}$ conformation is a low-humidity form.

W. Fuller A. Mahensdasingam V. T. FORSYTH

Department of Physics,

University of Keele,

Staffordshire ST5 5BG, UK

SAEnger ET aL. REPLY - Fuller et al. doubt our hypothesis ${ }^{1}$ because of data $^{+}$ from $\mathrm{X}$-ray fibre diffraction showing that (1) some excess $(3-6 \%) \mathrm{NaCl}$ must be added to DNA to pull well-ordered fibres; (2) with lower concentrations of salt, the $\mathrm{A} \rightarrow \mathrm{B}$ transition is inhibited or does not take place even if the relative humidity is above the critical $92 \%$; and (3) the $\mathrm{A} \rightarrow \mathrm{B}$ transition occurs above $92 \%$ relative humidity when DNA fibres contain $\sim 10 \%$ $\mathrm{NaCl}$. Careful interpretation of ref. 4 shows that it does not invalidate but rather provides support for our proposal.

First, at low $(<6 \%) \mathrm{NaCl}$ content at $75 \%$ relative humidity, Na-DNA fibres yield good A-form X-ray patterns because they are highly crystalline. They transform very slowly or not at all into the B-form if the relative humidity is $>92 \%$. We assume that DNA retains the $\mathrm{A}$-form resulting from lattice effects because even at high humidity, crystalline A-DNA fibres tend to remain in that "metastable" form whereas unoriented (non-crystalline) A-DNA gels reproducibly transform to B-DNA at $92 \%$ relative humidity "and remain in that form all the way into solution"s.

Second, at concentrations of $\sim 10 \%$ in the fibres, excess $\mathrm{NaCl}$ crystallizes out ${ }^{4}$, and these samples transform to the B-form at relative humidities $>92 \%$. We conclude that excess $\mathrm{NaCl}$ has a destabilizing effect on the Na-DNA crystalline lattice and transformation to B-DNA occurs as observed with A-DNA gels 5 .

Third, solid-state two-dimensional NMR shows that crystalline films (equivalent to fibres) of A-DNA at $\sim 3 \% \mathrm{NaCl}$, $75 \%$ relative humidity contain up to $60 \%$ disordered $\mathrm{B}-\mathrm{DNA}{ }^{11}$. This $\mathrm{B}-\mathrm{DNA}$ is not detected by $\mathrm{X}$-rays, which monitor only the crystalline A-DNA. So, in A-DNAtype fibres, partial transformation to the B-form could have occurred already as it would not be seen by diffraction methods.

Finally, the authors of ref. 4 support our proposal' in their last sentence: ". . . the salts . . . cause the fibres at high humidity to take up extra water with consequent dissolution of the $\mathrm{A}$ crystallites and formation of the semi-crystalline B form, which is more highly hydrated". This is the essence of our paper ${ }^{1}$ in which we describe why B-DNA is more highly hydrated than A- and Z-DNA. There is a threshold water activity where transitions between highly hydrated B-form and the less hydrated $\mathrm{A}$ - and Z-forms occur, no matter whether DNA is in the fibre state or in solution ${ }^{12.13}$.

We have not considered poly $[\mathrm{d}(\mathrm{A}-\mathrm{T})]$ because DNAs with special base sequences can behave differently because of the formation of ordered water structures (spine of hydration) in minor and/or major grooves ${ }^{14}$. We made clear in our paper that our proposal was for mixedsequence DNA and for poly $[\mathrm{d}(\mathrm{G}-\mathrm{C})]$.

W. SAENGER

Institut für Kristallographie,

Freie Universität Berlin,

D-1000 Berlin 33, FRG

W. N. HUNTER

O. KENNARD

University Chemical Laboratory,

Lensfield Road,

Cambridge CB2 1EW, UK

Saenger. W. . Hunter. W. N. \& Kennard. O. Nature 324 $385-388(1986)$

Frank-Kamenetskii. M. Nature 324, 305 (1986)

3. Texter. J. Prog. Biophvs. molec. Biol. 33, 83-97 (1978)

4. Cooper, P. J. \& Hamilton. L. D. J. molec. Biol. 16. 562 $563(1966)$

5. Erfurth. S. C.. Bond, P. J. \& Peticolas, W. I. Biopolymers 14. $1245-1257$ (1975).

6. Davies. D. R. \& Baldwin, R. L. J. molec. Biol. 6. 251 (1963). 7. Mahendrasingam. A. et al. Science 233, 195-197 (1986).

8. Forsyth, V. T. et al. Biochem. soc. Trans. 14. 553 (1986)

Mahendrasingam, A. et al. Nature 301, 535-537 (1983)

0 .Arnott, S. et al. Nucleic Acids Res. 11, 1457-1474 (1983)

1. Brandes. R. Vold. R. R. \& Kearns. D. R. Biopolymers 27. $1159-1170$ (1988).

2. Ivanov. V. I. et al. Biopolymers 12,89-100 (1973).

3. Wang. Y.. Thomas. G. A. \& Peticolas. W. L. J. biomolec. Struct. Dynam. 5, 249-274 (1987).

14. Kopka, M. L. et al. J. molec. Biol. 163, 129-146 (1983). 